\title{
Does Greek Foot Predispose to Morton's Neuroma?
}

\author{
Christopher Jump1, Michael Rice1, Daniel Gheorghiu², Jordi Sanchez-Ballester² \\ ${ }^{1}$ Liverpool Medical School, University of Liverpool, Liverpool, UK \\ ${ }^{2}$ Department of Orthopaedics and Trauma, St. Helens and Knowsley NHS Trust, Liverpool, UK \\ Email: cmjump1@gmail.com
}

Received 12 May 2014; revised 26 June 2014; accepted 11 July 2014

Copyright (C) 2014 by authors and Scientific Research Publishing Inc.

This work is licensed under the Creative Commons Attribution International License (CC BY).

http://creativecommons.org/licenses/by/4.0/

(c) (i) Open Access

\section{Abstract}

Background: Morton's neuroma is the enlargement of an interdigital nerve most commonly located between the third and fourth metatarsals. Greek foot is a normal variant where the first metatarsal is shorter than the second metatarsal. To our knowledge, there is currently no reported association between Greek foot and Morton's neuroma in the literature. Methods: Retrospective study of 184 patients. Two separate cohorts were recruited. Cohort A comprised of 100 randomly selected asymptomatic patients. Cohort B comprised of 84 patients with a history of foot pain and histologically confirmed Morton's neuroma. Foot shape was determined by using a selfassessment tool and plain radiographs. Statistical analyses were performed using the Chi-square test on the association between Greek foot and Morton's neuroma. A p-value of $<0.05$ was considered statistically significant. Results: Our study shows a statistically significant association between Greek foot and Morton's neuroma with a prevalence of Greek foot in Cohort $A$ of $20 \%$ and in Cohort B of $63 \%$. $\left(p=2.6 \times 10^{-9}\right)$. Conclusions: This study has shown a possible association between the presence of a Greek foot and the presence of Morton's neuroma. Although our study design has limitations and does not allow full statistical analysis, we do believe that the shown association between Greek foot and Morton's neuroma can help clinicians and other health care providers in establishing the diagnosis of Morton's neuroma in patients with a painful foot.

\section{Keywords}

Morton's Neuroma, Greek Foot, Egyptian Foot, Foot Pain

\section{Introduction}

Morton's neuroma was first recognised by Lewis Durlacher in 1845, who described it as "a neuralgic affection” 
[1]. It was then reported in 1876 by the surgeon Thomas G. Morton as a localised pathology of the metatarsals, caused by hypertrophy of the distal part of the lateral plantar nerve [2]. Morton's neuroma is a common cause of foot pain, with a mean age of presentation between 45 and 50 years [3]. It is more common in females with a female:male ratio of 5:1 [4].

Although the name suggests that this condition is not considered to be a true neuroma as there is no tumour formation. Instead it is thought to be an entrapment neuropathy causing perineural fibrosis, nerve degeneration, leukocyte infiltration and epineural and endoneural vascular hyalinization, resulting in a thicker nerve that is even more susceptible to entrapment [5].

The aetiology of Morton's neuroma is yet to be fully understood, although a few hypotheses exist. These include inflammation of the interdigital nerve [6], digital artery occlusion causing nerve ischaemia [7], entrapment at the edge of the transverse intermetatarsal ligament [8] and compression of the nerve via swollen bursae [9]. Another causative factor, which also explains that the increased incidence of Morton's neuroma in middle-aged females is the use of high-heeled, narrow-pointed shoes, which cause an increase in pressure on the forefoot, hyperextension of themetatarsophalangeal joints and force the metatarsal heads together, resulting in the compression of the interdigital nerves against the transverse metatarsal ligament and adjacent metatarsal heads [10]. It is believed that many of these factors could be the cause of the characteristic pain associated with Morton's Neuroma, however it is more likely a combination of these factors are acting together.

Morton's neuroma most commonly affects the third interdigital nerve but may also include the second, first and fourth nerves [11]-[13]. The increased presentation of the condition with the third common digital nerve is thought to be due to its increased susceptibility to trauma, as unlike the other interdigital nerves it consists of branches from the medial and lateral plantar nerve, which cause increased thickness making it more prone to repetitive trauma and therefore the formation of perineural fibrosis [14]. Another reason for the increased presentation could be due to the third nerve being tethered by a branch communicating to the fourth web space, causing shearing forces to be applied to the restricted third common digital nerve by the movement of the more mobile fourth metatarsal head resulting in repetitive injuries upon the edge of the ligament [15].

Morton's neuroma usually presents with pain or a tingling or burning sensation at the distal end of the adjacent metatarsal heads radiating to the affected toes and the sensation of walking with a stone under the forefoot. The pain can usually be relieved by the removal of shoes, rest and manipulation of the foot [5]. These clinical features are also common in other foot conditions such as metatarsalgia, synovitis or instability, and can therefore make diagnosis difficult. Other differential diagnoses are stress fractures and less commonly infection, tumour or Frieberg's infraction.

On examination a positive Mulder's sign is elicited, which is the production of a palpable, painful clicking sound when the interspace is palpated whilst the metatarsal heads are compressed laterally, causing the neuroma to be subluxed beneath the transverse metatarsal ligament [16] (Figure 1).

Diagnosis is usually confirmed by the use of Radiographs, Ultrasound or Magnetic Resonance Imaging (MRI). However, it has been reported that physical examination and the production of Mulder's sign is still the most sensitive and specific method of diagnosing Morton’s Neuroma [17]-[20]. Morton’s neuroma can be managed conservatively using arch supports, wearing wide toe box shoes, avoidance of high-heels, and padding or taping with the aim of dispersing weight bearing from the site of the neuroma to avoid compression and therefore symptoms. Corticosteroid injections are also frequently used to control symptoms. These conservative measures are effective in over $50 \%$ of cases [6] [21]. When these interventions fail a surgical excision of the neuroma is

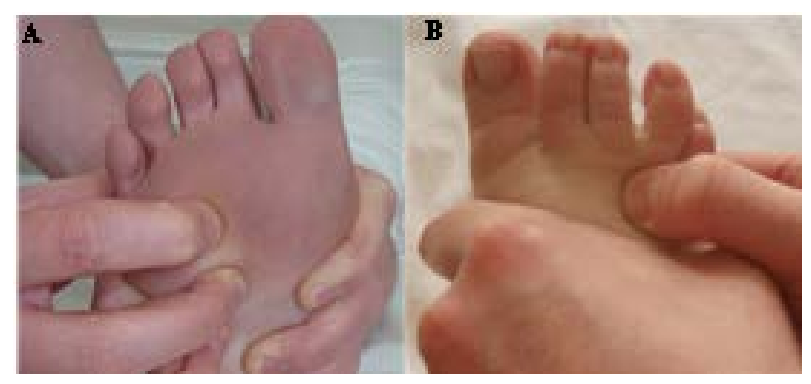

Figure 1. Compression test of a Morton's neuroma from the plantar (A) and dorsal (B) aspects. 
performed, which is curative in $80 \%$ of patients [22]-[24].

If not treated Morton's neuroma can continue to enlarge causing increasingly severe foot pain that can be disabling. Chronically the pain can cause a compensatory change in gait in an attempt to relieve the pain, which can cause further problems in the back, hip, knee and ankle [24].

The procedure for removing an interdigital neuroma has changed multiple times since the first successful excision from the third web space was performed by A.E. Hoadley in 1883 [25]. Since then there have been a number of procedures used to treat patients including: isolated transverse metatarsal ligament division, isolated inter-digital nerve excision, and then a combination of interdigital nerve excision with transverse ligament division [26] [27].

Commonly the combination of nerve excision and ligament division is used. In the past isolated nerve excision was chosen due to concerns that division of the ligament would result in the foot being splayed post-operatively, this has since been disproven [28].

It is now thought that simple nerve excision (primary digital neurectomy) without ligament division leads to an increase in postoperative side effects, including recurrence of pain as without division of the ligament a symptomatic stump neuroma is formed [22] [29].

Generally it has been agreed that primary surgery should be performed through the dorsal aspect of the foot as it allows earlier weight bearing and a quicker recovery [30]. The plantar approach is often used in secondary surgeries, such as revisions of a recurrent stump neuroma, as it provides much better exposure to the proximal nerve trunk [31] [32]. Commonly those undergoing the dorsal approach can weight bear immediately and skin sutures are removed after approximately 12 days. Patients undergoing the plantar approach usually have weight bearing and suture removal delayed for at least 14 days and usually progress to wearing a normal shoe after 4 weeks [30].

Greek Foot is a normal variant in which there is a congenital shortening of the first metatarsal in relation to the second metatarsal bone (Figure 2(A)). This results in a hallux that appears to be shorter than the second phalanx and is a common type of brachymetatarsia [33]. Greek Foot was originally known as Morton's Foot after the surgeon Dudley Morton who described the variant as Metatarsus atavicus, and reported its prevalence as $10 \%$ of the population [34]. An Egyptian foot is the name given to a foot in which the first metatarsal bone is longer than the second (Figure 2(B)).

There is no evidence in the current literature of a correlation between Greek foot and Morton's neuroma. However, Dudley Morton [34] suggested that there may be a link between a congenitally short first metatarsal and symptoms of foot pain, which he concluded could not be differentiated from those described earlier by T.G. Morton [2], that were later attributed to Morton's neuroma. In addition, several of the cases described by T.G. Morton had radiographs demonstrating Greek foot.

The aim of this study was to investigate if Greek foot predisposes to Morton's neuroma. This would be an important finding as it would not only aid with the diagnosis of Morton's neuroma but also enable the detection of people who are at risk of developing the condition and allow primary preventative measures to be taken such

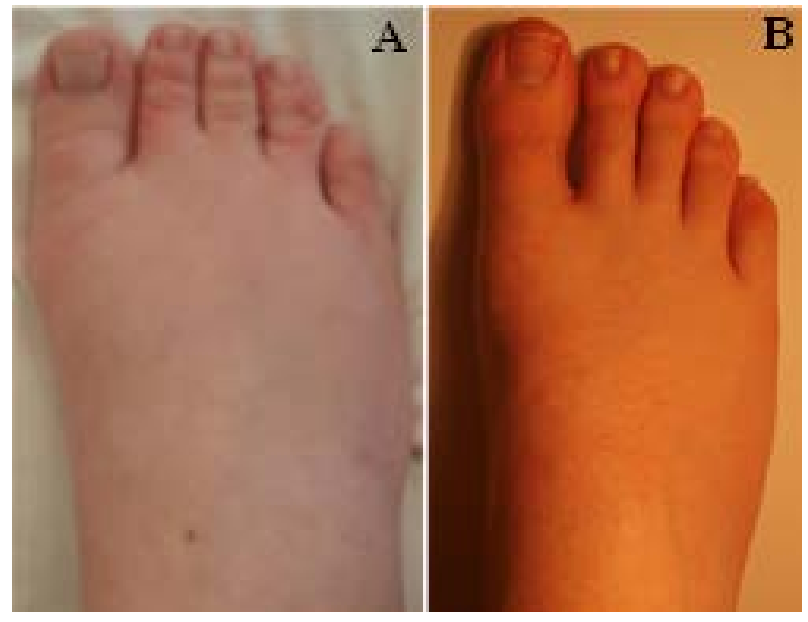

Figure 2. Photographs of a Greek (A) and Egyptian foot (B). 
as the avoidance of high-heels. Such early intervention could result in fewer patients requiring surgery for Morton's neuroma, therefore subjecting fewer patients to the potential complications of neurectomy, which include infection, wound dehiscence, haematoma, persistent or recurrent pain, swelling, numbness, anaesthesia-related and stump neuroma [24] [26] [35]. It would also reduce the costs of patient care, for which theatre time is one of the largest expenses to healthcare providers.

\section{Method}

Retrospective study of 217 patients from a Caucasian population. Sample size was determined by the time limitations of the study. Eligible participants included people of 18 years of age or older.

Cohort A was a control group consisting of 133 randomly selected participants. 33 patients were excluded from the study due to the presence of foot pain.

Foot variant was determined by using a self-assessment tool.

Cohort B consisted of 84 patients who had undergone surgical excision of histologically confirmed Morton's neuroma between 2003 and 2011.

Assessment of foot variant was performed by reviewing weight-bearing plain radiographs. Participants were deemed to have a Greek foot if the first metatarsal bone was shorter than the second metatarsal and an Egyptian foot if the first metatarsal bone was longer than the second.

Statistical analysis in the form of a Chi-squared test was performed to assess association between Greek foot and Morton’s Neuroma. A p-value of $<0.05$ was considered statistically significant.

\section{Results}

\subsection{Cohort A}

Cohort A included 133 participants. 33 were excluded due to experiencing foot pain.

Mean age was 55.5 years (range 19 - 88). Cohort A consisted of 62 females and 38 males with a female-tomale ratio of 1.6:1.

80 (80\%) participants had Egyptian foot variant and 20 (20\%) demonstrated Greek foot (Figure 3).

\subsection{Cohort B}

Mean age was 54.3 years (range 19 - 87).

There were 70 females and 14 males, resulting in a female to male ratio of 5:1.

53 (63\%) participants were found to have Greek foot and 31 (37\%) had Egyptian foot (Figure 3).

\subsection{Statistical Analysis}

A Chi-squared test was used to measure the association between Greek foot and Morton's neuroma. The calculation produced a result of $35.4\left(\mathrm{p}=2.6 \times 10^{-9}\right)$.

\section{Discussion}

In 1927 the worldwide prevalence of Greek foot was estimated to be around 10\% by Dudley Morton [34]. This study shows the prevalence of Greek foot in individuals with no foot pain to be $20 \%$ (95\% C.I.: $12 \%$ to $28 \%$ ). The self-assessment tool used in Cohort A relied on participants to identify their own foot variant. It was recognised beforehand that this may be difficult due to patients having debatable foot variants, however it was agreed that this method was safer and less expensive than subjecting participants to radiation. During data collection no problems were encountered in detecting foot shape as patients were easily able to identify their foot variant. Therefore the suspected limitation has been deemed not to have affected the results. The results of Cohort B demonstrated that 63\% (95\% C.I.: 53\% to 73\%) of patients with Morton's neuroma had Greek foot. Analysis of the cohorts using a chi-squared test produced a statistically significant association between Greek foot and Morton's neuroma $\left(\mathrm{p}=2.6 \times 10^{-9}\right)$.

Although this result is significant we are unable to conclusively prove association due to limitations in study design preventing full statistical analysis, therefore necessitating further studies. One such limitation was due to the sample population used in Cohort B being taken from a population already diagnosed with Morton's neuroma 

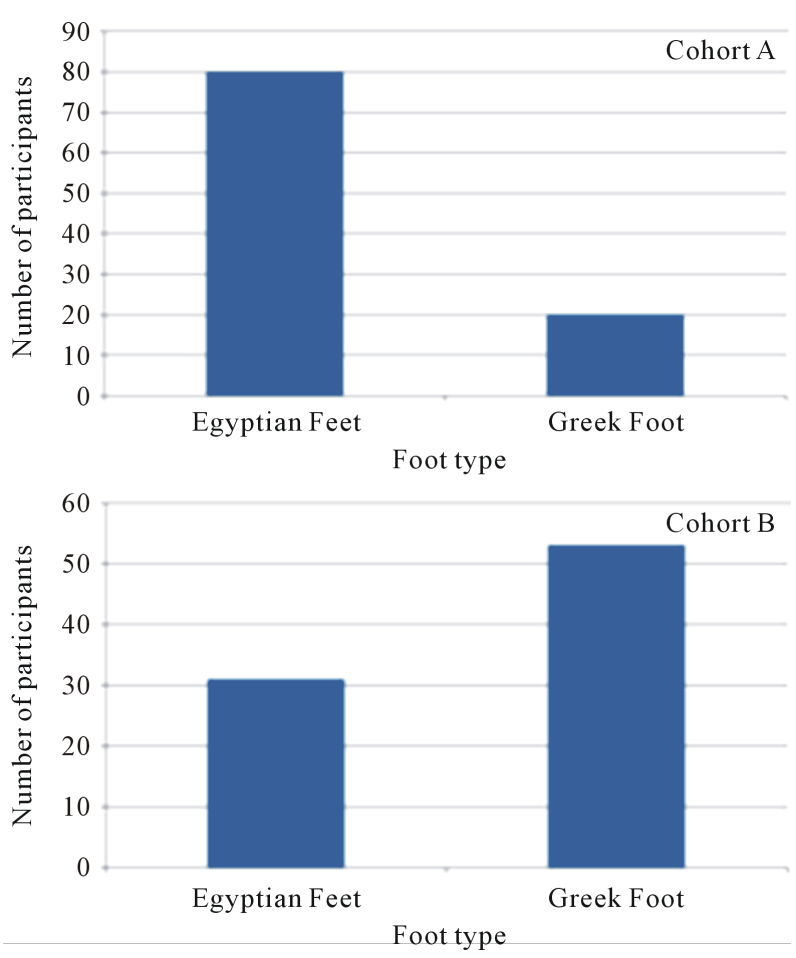

Figure 3. Bar charts to show the relative number of participants with Egyptian and Greek foot types in Cohort A (asymptomatic population) and Cohort B (Morton's neuroma patients).

resulting in selection bias. Furthermore the assessment of Greek foot in both cohorts was made using different techniques. Although these limitations exist the study has shown a possible association between Greek foot and Morton's neuroma.

This association could be explained by the differences in weight bearing between individuals with Greek and Egyptian Foot variants. In an Egyptian foot the functional axis lies between the first and second metatarsal bones, therefore during walking, the body weight passes mostly over the larger first metatarsal. However in a Greek foot the presence of a longer second metatarsal bone causes the functional axis of the foot to move laterally to that of the longitudinal axis of the second metatarsal bone [34]. This could place excessive stress on the metatarsal bones of the lateral part of the foot, which are not able to cope due to their relatively weak plantar ligaments compared to that attached to the first metatarsal bone. This repetitive stress whilst walking in addition to the larger first metatarsal head of Greek foot causing lateral compression could result in entrapment of an interdigital nerve and Morton's neuroma.

This association is an important finding as the presence of Greek foot could help clinicians establish the diagnosis of Morton's neuroma in patients presenting with a painful foot. It could also allow advice and preventative measures to be given to patients with Greek foot to help prevent the development of Morton's neuroma and any subsequent pain and disability.

\section{Conclusion}

This study shows the prevalence of Greek foot in individuals with no foot pain to be $20 \%$ (95\% C.I.: $12 \%$ to 28\%) and the prevalence of Greek foot in patients with Morton's neuroma to be 63\% (95\% C.I.: 53\% to 73\%). This demonstrates a possible association between Greek foot and Morton's neuroma. It also shows that the prevalence of Greek foot is higher in patients with Morton's neuroma than in the asymptomatic population. Although a statistically significant association between Greek foot and Morton's neuroma $\left(\mathrm{p}=2.6 \times 10^{-9}\right)$ can be shown, a limited study design prevents full statistical analysis. However, we believe that the results are promising and that identification of Greek foot can help clinicians to establish a diagnosis of Morton's neuroma. 


\section{Acknowledgements}

We would like to thank Dr. Stephen Raftery of St. Helens and Knowsley NHS Trust for helping with the statistical analysis in this study.

\section{References}

[1] Durlacher, L. (1945) A Treatise on Corns, Bunions, the Diseases of Nails, and the General Management of Feet. Simpkin, Marshall and Co., London.

[2] Morton, T. (1876) A Peculiar and Painful Affection of the Fourth Metatarso-Phalangeal Articulation. American Journal of the Medical Sciences, 71, 37-45. http://dx.doi.org/10.1097/00000441-187601000-00002

[3] Lorimer, D.L. and Neale, D. (2002) Neale’s Disorders of the Foot: Diagnosis and Management. 6th Edition, Churchill Livingstone, Edinburgh, New York, 714 p.

[4] Brubaker, N. (2008) Morton’s Neuroma. The Journal of Nursing, 4, 785-786.

[5] Bencardino, J., Rosenberg, Z.S., Beltran, J., Liu, X. and Marty-Delfaut, E. (2000) Morton's Neuroma: Is It Always Symptomatic? American Journal of Roentgenology, 175, 649-653. http://dx.doi.org/10.2214/ajr.175.3.1750649

[6] Dereymaeker, G., Schroven, I., Steenwerckx, A. and Stuer, P. (1996) Results of Excision of the Interdigital Nerve in the Treatment of Morton's Metatarsalgia. Acta Orthop\&aeligdica Belgica, 62, 22-25.

[7] Nissen, K.I. (1948) Plantar Digital Neuritis; Morton’s Metatarsalgia. Journal of Bone and Joint Surgery, 30B, 84-94.

[8] Gauthier, G. (1979) Thomas Morton’s Disease: A Nerve Entrapment Syndrome. A New Surgical Technique. Clinical Orthopaedics and Related Research, 142, 90-92.

[9] Bossley, C.J. and Cairney, P.C. (1980) The Intermetatarso-Phalangeal Bursa-Its Significance in Morton’s Metatarsalgia. Journal of Bone and Joint Surgery, 62, 184-187.

[10] Wu, K.K. (1996) Morton's Interdigital Neuroma: A Clinical Review of Its Etiology, Treatment, and Results. Journal of Foot and Ankle Surgery, 35, 112-119. http://dx.doi.org/10.1016/S1067-2516(96)80027-5

[11] Addante, J.B., Peicott, P.S., Wong, K.Y. and Brooks, D.L. (1986) Interdigital Neuromas. Results of Surgical Excision of 152 Neuromas. Journal of the American Podiatric Medical Association, 76, 493-495. http://dx.doi.org/10.7547/87507315-76-9-493

[12] Bradley, N., Miller, W.A. and Evans, J.P. (1976) Plantar Neuroma: Analysis of Results Following Surgical Excision in 145 Patients. Southern Medical Journal, 69, 853-854. http://dx.doi.org/10.1097/00007611-197607000-00014

[13] Coughlin, M. and Mann, R. (2001) Foot and Ankle Surgery. Mosby, St Louis.

[14] Jones, J.R. and Klenerman, L. (1984) A Study of the Communicating Branch between the Medial and Lateral Plantar Nerves. Foot \& Ankle International, 4, 313-315. http://dx.doi.org/10.1177/107110078400400608

[15] Betts, L. (1940) Morton’s Metatarsalgia. Medical Journal, 1, 514-515.

[16] Mulder, J.D. (1951) The Causative Mechanism in Morton’s Metatarsalgia. Journal of Bone and Joint Surgery, 33, 9495.

[17] Terk, M.R., Kwong, P.K., Suthar, M., Horvath, B.C. and Colletti, P.M. (1993) Morton Neuroma: Evaluation with MR Imaging Performed with Contrast Enhancement and Fat Suppression. Radiology, 189, 239-241. http://dx.doi.org/10.1148/radiology.189.1.8372200

[18] Resch, S., Stenstrom, A., Jonsson, A. and Jonsson, K. (1994) The Diagnostic Efficacy of Magnetic Resonance Imaging and Ultrasonography in Morton's Neuroma: A Radiological-Surgical Correlation. Foot \& Ankle International, 15, 8892. http://dx.doi.org/10.1177/107110079401500208

[19] Zanetti, M., Strehle, J.K., Zollinger, H. and Hodler, J. (1997) Morton Neuroma and Fluid in the Intermetatarsal Bursae on MR Images of 70 Asymptomatic Volunteers. Radiology, 203, 516-520. http://dx.doi.org/10.1148/radiology.203.2.9114115

[20] Sharp, R.J., Wade, C.M., Hennessy, M.S. and Saxby, T.S. (2003) The Role of MRI and Ultrasound Imaging in Morton's Neuroma and the Effect of Size of Lesion on Symptoms. Journal of Bone and Joint Surgery, 85, 999-1005. http://dx.doi.org/10.1302/0301-620X.85B7.12633

[21] Bennett, G.L., Graham, C.E. and Mauldin, D.M. (1995) Morton’s Interdigital Neuroma: A Comprehensive Treatment Protocol. Foot \& Ankle International, 16, 760-763. http://dx.doi.org/10.1177/107110079501601204

[22] Mann, R.A. and Reynolds, J.C. (1983) Interdigital Neuroma-A Critical Clinical Analysis. Foot \& Ankle International, 3, 238-243. http://dx.doi.org/10.1177/107110078300300411

[23] Friscia, D.A., Strom, D.E., Parr, J.W., Saltzman, C.L. and Johnson, K.A. (1991) Surgical Treatment for Primary Interdigital Neuroma. Orthopedics, 14, 669-672. 
[24] Anwar, F. (2010) Morton’s Neuroma- Outcome of Surgical Excision. Journal of Orthopaedics, 7, e8.

[25] Hoadley, A.E. (1893) Six Cases of Metatarsalgia. Chicago Medication Reconciliation, 5, 32.

[26] McGlamry, E.D. and Banks, A.S. (2001) McGlamry’s Comprehensive Textbook of Foot and Ankle Surgery. 3rd Edition, Lippincott Williams \& Wilkins, Philadelphia, 66 p.

[27] Thomson, C.E., Gibson, J.N. and Martin, D. (2004) Interventions for the Treatment of Morton's Neuroma. Cochrane Database of Systematic Reviews, 3, Article ID: CD003118.

[28] Hamilton, W.G. (1992) Morton's Neuroma Surgery. The Foot: Surgical Update Seattle. AAOS Summer Institute, Washington DC.

[29] Coughlin, M.J. and Pinsonneault, T. (2001) Operative Treatment of Interdigital Neuroma. A Long-Term Follow-Up Study. Journal of Bone and Joint Surgery (American Volume), 83, 1321-1328.

[30] Sing, S.K., Ioli, J.P. and Chiodo, C.P. (2005) The Surgical Treatment of Morton's Neuroma. Current Orthopaedics, 19, 379-384. http://dx.doi.org/10.1016/j.cuor.2005.07.004

[31] Johnson, J.E., Johnson, K.A. and Unni, KK. (1988) Persistent Pain after Excision of an Interdigital Neuroma. Results of Reoperation. Journal of Bone and Joint Surgery (American Volume), 70, 651-657.

[32] Beskin, J.L. and Baxter, D.E. (1988) Recurrent Pain Following Interdigital Neurectomy-A Plantar Approach. Foot \& Ankle International, 9, 34-39. http://dx.doi.org/10.1177/107110078800900107

[33] Schimizzi, A. and Brage, M. (2004) Brachymetatarsia. Foot and Ankle Clinics, 9, 555-570. http://dx.doi.org/10.1016/j.fcl.2004.05.002

[34] Morton, D. (1927) Metatarsus Atavicus: The Identification of a Distinct Type of Foot Disorder. Journal of Bone and Joint Surgery (American Volume), 9, 531-544.

[35] Coughlin, M.J. (2000) Common Causes of Pain in the Forefoot in Adults. Journal of Bone and Joint Surgery, 82, 781790. http://dx.doi.org/10.1302/0301-620X.82B6.11422 
Scientific Research Publishing (SCIRP) is one of the largest Open Access journal publishers. It is currently publishing more than 200 open access, online, peer-reviewed journals covering a wide range of academic disciplines. SCIRP serves the worldwide academic communities and contributes to the progress and application of science with its publication.

Other selected journals from SCIRP are listed as below. Submit your manuscript to us via either submit@scirp.org or Online Submission Portal.
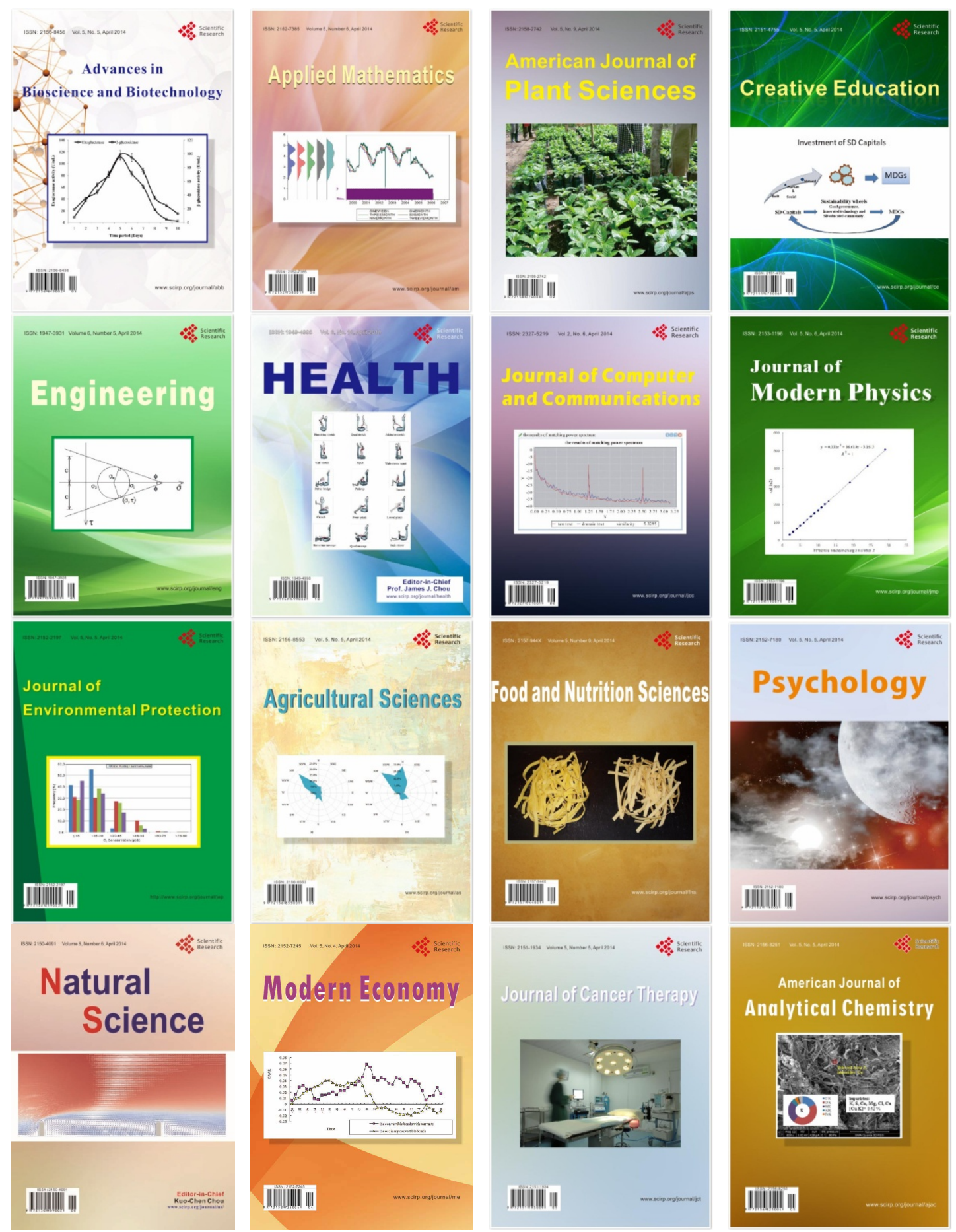